\title{
PENDETEKSI KEB OCORAN GAS DAN KEBAKARAN BERBASIS ARDUINO DENGAN ANTARMUKA VISUAL BASIC
}

\author{
Givy Devira Ramady ${ }^{1}$, Rahmad Hidayat ${ }^{2 *}$, Syafruddin $\mathbf{R}^{3}$, Andrew Ghea Mahardika ${ }^{4}$, Anjeng Sun Sun ${ }^{5}$ \\ Email : givy.d.ramady@gmail.com, rhidayat4000@gmail.com, syafruddinr@yahoo.com, andrewhinata@gmail.com, \\ sunsunanjeng@gmail.com, \\ Program Studi Teknik Elektro, Sekolah Tinggi Teknologi Mandala, Bandung
}

\begin{abstract}
Abstrak
Di dalam sektor industri terdapat sumber potensi yang dapat memicu terjadinya kebakaran. Kebakaran di tempat kerja dapat membawa konsekuensi yang berdampak merugikan banyak pihak. Fire alarm system merupakan sebuah sistem yang dirancang untuk memberikan early warning terjadinya kebakaran atau gejala terjadinya kebakaran kepada pekerja di dalam bangunan gedung. Untuk itu keakurasian dan kecepatan dalam membaca titik yang menyebabkan kebakaran harus diperhitungkan khususnya pada pemakaian sensor, kabel transmisi data, serta pemetaan suatu area. Pada penelitian ini, alat dirancang dan direalisasikan menggunakan sensor gas tipe MQ-135. Sensor gas MQ-135 merupakan jenis sensor kimia yang sensitif terhadap gas dalam tabung LPG, alkohol, benzol, gas, dan lain-lain. Sensor gas MQ-135 nantinya akan dilengkapi dengan sensor suhu (DHT-11). Indikasi kebakaran yang diperoleh ditampilkan pada aplikasi antarmuka Visual Basic, tiga buah LED, buzzer dan motor DC. Hasil pengujian pada realisasi sistem menunjukkan sensor MQ-135 dan DHT-11 mampu berfungsi dengan baik pada berbagai jarak uji. Begitu pula dengan aplikasi antarmuka yang dapat menampilkan informasi sesuai data pembacaan pada sistem.
\end{abstract}

Kata kunci : Gas, Kebocoran, Kebakaran, Sensor

\section{Pendahuluan}

Kebakaran dapat terjadi kapan saja dan dimana saja. Tidak ada tempat kerja yang terjamin bebas resiko dari bahaya kebakaran. Kebakaran di tempat kerja dapat membawa konsekuensi yang berdampak merugikan banyak pihak. Kebakaran dalam sektor industri dapat terjadi karena beberapa faktor seperti material atau sampah yang mudah terbakar yang tersimpan di dalam ruang kantor, cairan dan gas yang mudah terbakar, peralatan listrik, overloading stop kontak, rokok, dan akibat kesalahan manusia.

Fire alarm system adalah sebuah sistem yang dirancang untuk memberikan informasi terjadinya kebakaran atau gejala terjadinya kebakaran kepada penghuni/pemakai bangunan gedung, kepada petugas jaga dan anggota pemadam kebakaran. Sistem ini akan mengetahui gejala kebakaran lebih dini sehingga letak kebakaran segera diketahui dan api tidak membesar dan dapat segera dipadamkan.

Tujuan utama dalam merancang dan merealisasikan sebuah alat dalam mendeteksi kebocoran gas dan kebakaran yaitu untuk menjamin terciptanya rasa aman; agar dapat memonitoring dapur pada mesh dan seisi tempat produksi sehingga dapat meminimalkan terjadinya sebuah kebakaran pada gedung tersebut. Untuk itu keakurasian dan kecepatan dalam membaca titik yang menyebabkan kebakaran harus diperhitungkan.
Di dalam alat yang akan dirancang dan direalisasikan digunakan sensor gas tipe MQ$135^{[1,2]}$. Sensor gas MQ-135 merupakan jenis sensor kimia yang sensitif terhadap gas dalam tabung LPG, alkohol, benzol, gas, dan lainlain. Sensor gas MQ-135 nantinya akan dilengkapi dengan sensor suhu ${ }^{[3-5]}$. Indikasi kebakaran yang diperoleh ditampilkan pada Visual Basic, 3 buah LED, Buzzer dan motor DC. $^{[6,7]}$

\section{Metode Penelitian}

Metode yang digunakan pada penelitian ini di antaranya:

Metode deskriptif analitis, yaitu dengan cara menganalisa dan mengidentifikasi permasalahan yang muncul selama penelitian.

Studi Kepustakaan, yaitu dengan cara mengumpulkan informasi dari berbagai macam literatur yang akan dijadikan sumber serta panduan dalam penyusunan penulisan ini.

Sistem yang akan dirancang dan direalisasikan menggunakan sensor gas dengan tipe MQ-135. Sensor gas MQ-135 merupakan jenis sensor kimia yang sensitif terhadap gas dalam tabung LPG, alkohol, benzol, gas, dan lain-lain. Sensor gas MQ-135 nantinya akan dilengkapi dengan sensor suhu (DHT-11). Indikasi kebakaran yang diperoleh ditampilkan pada aplikasi antarmuka Visual Basic, 3 buah LED, Buzzer dan motor DC. 
Sensor DHT-11 dan MQ-135 akan dihubungkan dengan sebuah mikrokontroler Arduino. Sistem ini kemudian akan diisikan program agar dapat bekerja sesuai fungsi yang telah ditetapkan.

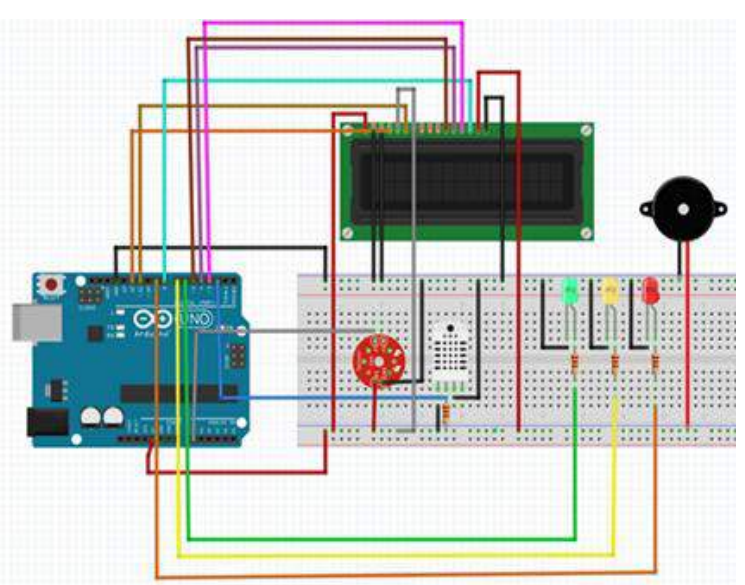

Gambar 1. Desain skema sistem

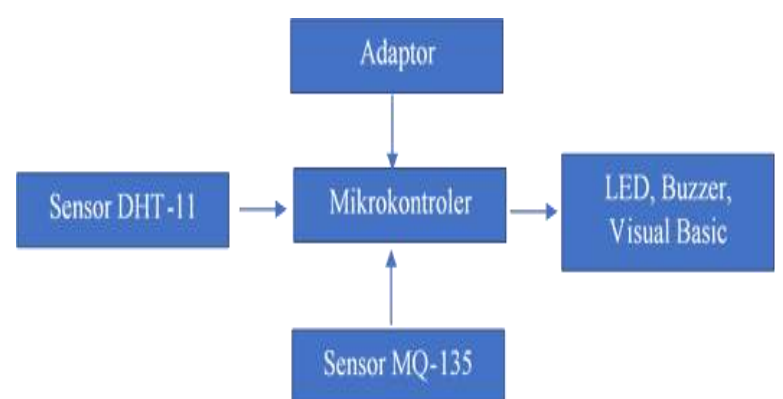

Gambar 2. Skema Kerja sistem

Sensor gas MQ-135 dan DHT-11 yang terpasang pada mikrokontroller Arduino akan melakukan pembacaan pada ruang uji. Hasil pembacaan ini kemudian akan dikirimkan untuk diproses oleh mikrokontroller. Data hasil pembacaan sensor lalu akan diolah untuk ditentukan indicator yang sesuai dengan algoritma yang diprogramkan pada mikrokontroller. Berdasarkan nilai indicator tersebut, selanjutnya akan memicu perangkat output berupa LED ataupun buzzer untuk dapat aktif atau tidak seperti pada gambar 3 .

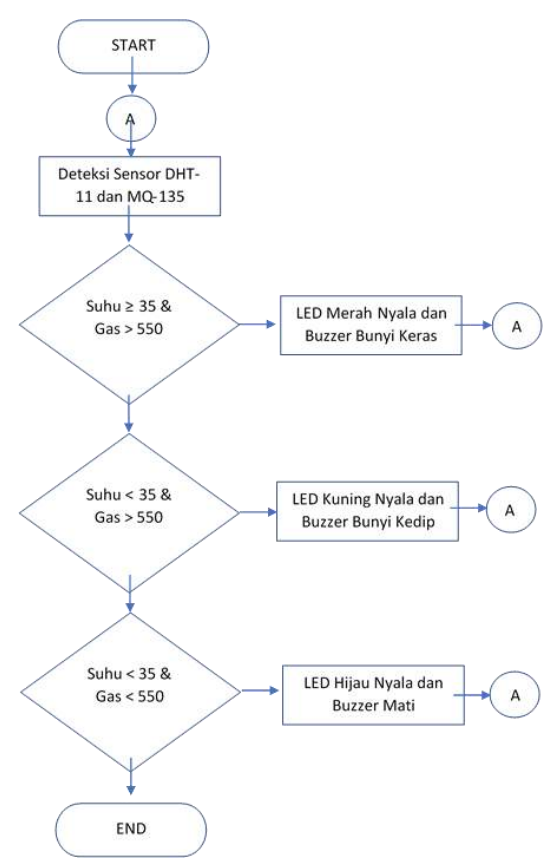

Gambar 3. Skema kerja sistem

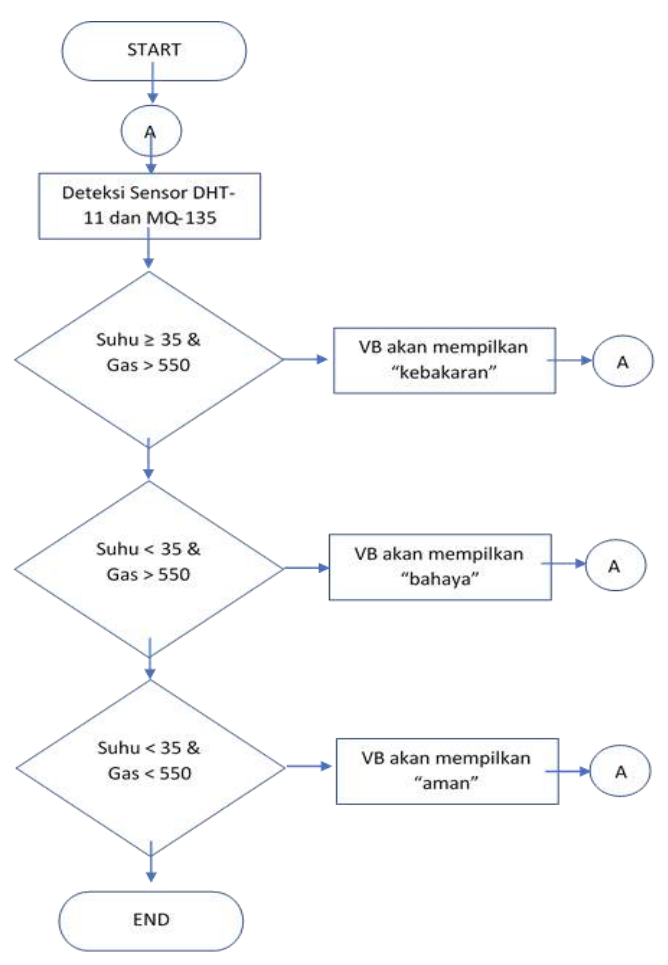

Gambar 4. Skema Kerja Aplikasi 
Berdasarkan gambar 4, aplikasi monitoring akan melakukan sinkronisasi nilai data pada sistem untuk menampilkannya pada layar pantau administrator.

\section{Hasil dan Pembahasan}

Pengujian dilakukan untuk mengetahui apakah fungsi - fungsi dari alat dan aplikasi yang telah dirancang dapat bekerja dengan baik atau tidak. Pengujian alat juga berguna untuk mengetahui tingkat kinerja dan fungsi tersebut. Pengujian yang dilakukan meliputi pengujian pada perangkat keras dan aplikasi.

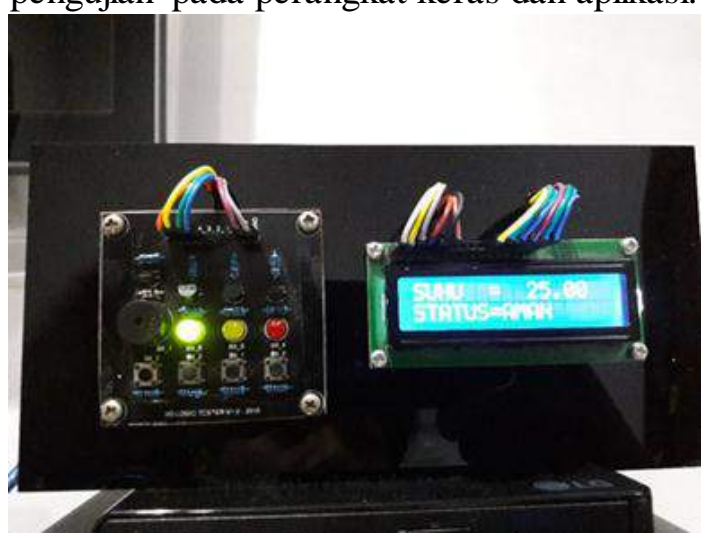

Gambar 5. Fire alarm system

Tabel 1. Pengujian Sensor Gas MQ-135

\begin{tabular}{|c|c|c|c|c|}
\hline NO & $\begin{array}{c}\text { JARAK } \\
\text { (CM) }\end{array}$ & $\begin{array}{c}\text { KUALITAS } \\
\text { UDARA }\end{array}$ & $\begin{array}{c}\text { INDIKATOR } \\
\text { SENSOR }\end{array}$ & $\begin{array}{c}\text { DELAY } \\
\text { (s) }\end{array}$ \\
\hline 1 & 1 & 240 & BAHAYA & 1 \\
\hline 2 & 3 & 190 & BAHAYA & 7 \\
\hline 3 & 5 & 138 & BAHAYA & 15 \\
\hline 4 & 8 & 128 & BAHAYA & 20 \\
\hline 5 & 10 & 121 & BAHAYA & 35 \\
\hline 6 & 15 & 111 & AMAN & - \\
\hline 7 & 20 & 105 & AMAN & - \\
\hline 8 & 25 & 99 & AMAN & - \\
\hline 9 & 30 & 98 & AMAN & - \\
\hline 10 & 35 & 97 & AMAN & - \\
\hline
\end{tabular}

HASIL UJI COBA SENSOR MQ-135 PADA JARAK BERBEDA

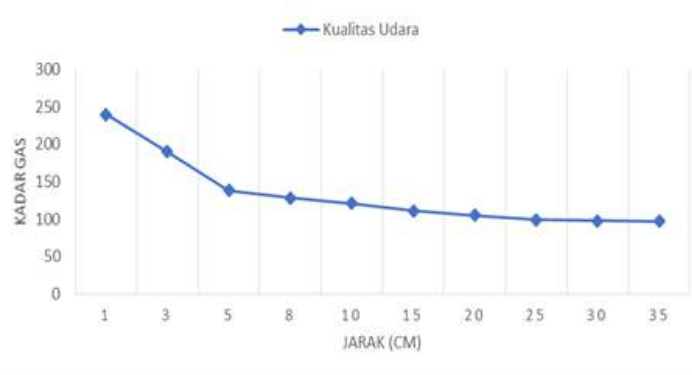

Gambar 6. Grafik hasil uji coba sensor MQ-135
Dari hasil pengujian sensor MQ-135 pada berbagai Jarak, dapat dilihat jarak yang berbeda akan mempengaruhi pembacaan sensor sehingga perlunya peletakan sensor yang dekat dengan sumber gas tersebut sehingga pembacaan sensor dapat maksimal. Semakin jauh jarak, sensor tidak dapat membaca kadar gas dengan benar.

Jauh dekatnya jarak yang diujicobakan memperlihatkan waktu yang diperlukan oleh sensor MQ-135 untuk membaca kadar gas juga akan semakin lama, hal itu disebabkan oleh tercampurnya gas dengan udara ruangan sehingga sensor perlu waktu agar dapat membaca gas dengan tepat.

Tabel 2. Pengujian Sensor DHT-11

\begin{tabular}{|c|c|c|c|c|}
\hline NO & $\begin{array}{c}\text { JARAK } \\
\text { (CM) }\end{array}$ & $\begin{array}{c}\text { SUHU } \\
\text { (c) }\end{array}$ & $\begin{array}{c}\text { INDIKATOR } \\
\text { SENSOR }\end{array}$ & DELAY(s) \\
\hline 1 & 1 & 34 & KEBAKARAN & 10 \\
\hline 2 & 3 & 32 & KEBAKARAN & 16 \\
\hline 3 & 5 & 31 & KEBAKARAN & 30 \\
\hline 4 & 8 & 29 & KEBAKARAN & 45 \\
\hline 5 & 10 & 28 & AMAN & - \\
\hline 6 & 15 & 28 & AMAN & - \\
\hline 7 & 20 & 28 & AMAN & - \\
\hline 8 & 25 & 28 & AMAN & - \\
\hline 9 & 30 & 27 & AMAN & - \\
\hline 10 & 35 & 27 & AMAN & - \\
\hline
\end{tabular}

HASIL UJI COBA SENSOR DHT-11 PADA JARAK BERBEDA

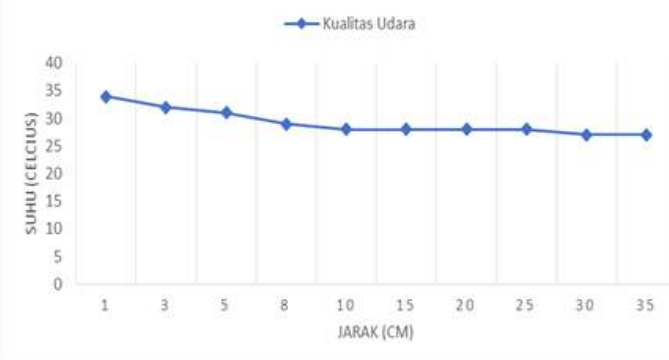

Gambar 7. Grafik hasil uji coba sensor DHT-11 Dari hasil pengujian sensor DHT-11 pada berbagai Jarak, dapat dilihat jarak yang berbeda akan mempengaruhi pembacaan sensor sehingga perlunya peletakan senor yang dekat dengan sumber gas tersebut sehingga pembacaan sensor dapat maksimal. Semakin jauh jarak, sensor tidak dapat membaca suhu dengan benar.

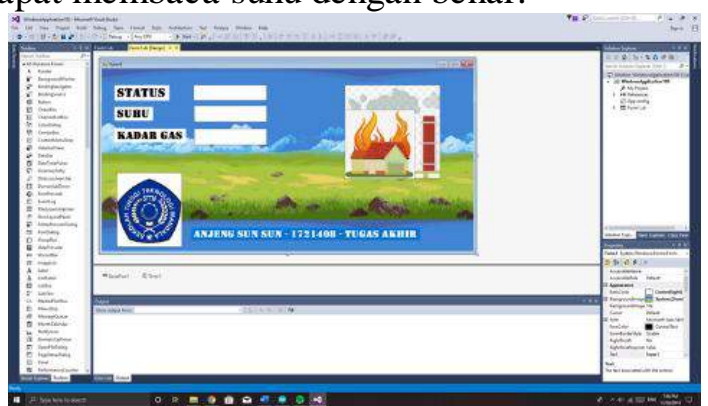

Gambar 8. Tampilan utama aplikasi 
Pengujian aplikasi dilakukan untuk mengetahui tingkat kinerja dan fungsi tersebut. Pada tampilan di Visual Basic ini dipengaruhi oleh pembacaan pada perangkat hardware, ketika hardware membaca keadaan aman akan muncul tampilan Visual Basic dalam keadaan aman juga, begitu pula jika terjadi kebocoran gas dan kebakaran tampilan akan menyesuaikan.

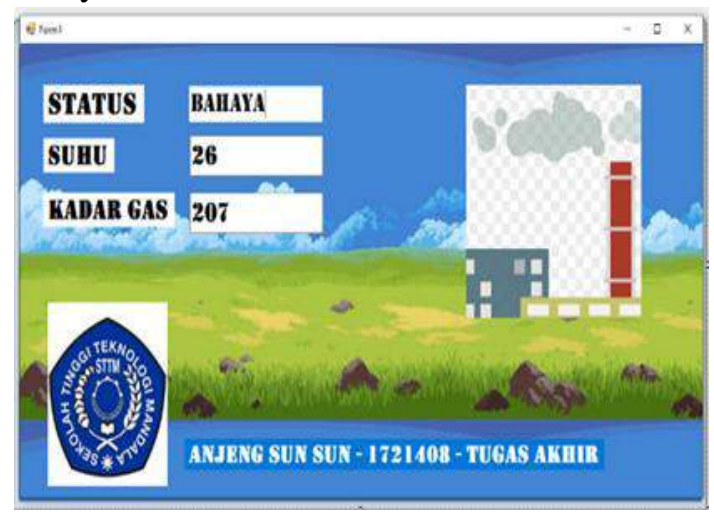

Gambar 9. Tampilan indikator bahaya

Pada saat kondisi bahaya, dimana kadar gas yang terbaca jauh dari batas aman yaitu diatas 120 , artinya terjadi kebocoran gas pada ruangan tersebut

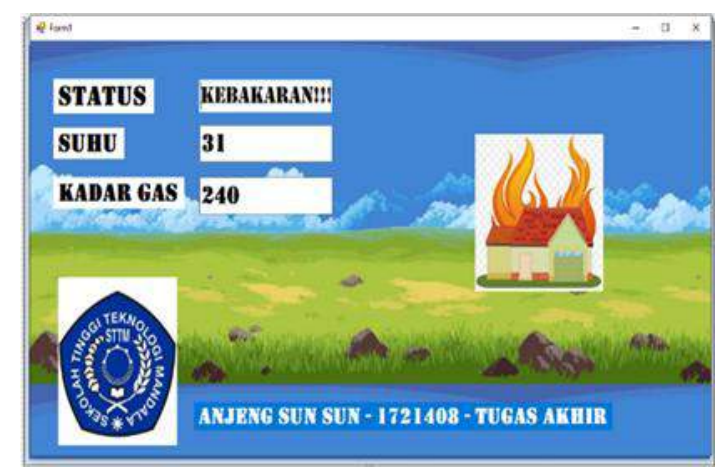

Gambar 10. Tampilan indikator kebakaran

Pada saat kondisi kebakaran dimana kadar gas yang terbaca jauh dari batas aman yaitu diatas 120 , artinya terjadi kebocoran gas pada ruangan tersebut. Tetapi suhu yang terbaca juga melebihi batas ambang $30^{\circ}$.

\section{Kesimpulan}

Setelah dilakukan pengujian terhadap sensor DHT-11 dan MQ-135 dapat ditarik kesimpulan dari keduanya, jika dilihat dari tiga faktor pengujian (jarak, tempat dan waktu) keduanya memiliki karakteristik yang cukup sama. Kedua sensor tersebut sama-sama dipengaruhi oleh jarak, artinya ketika jarak faktor penyebab kebakaran semakin dekat dengan sensor, sensor dapat membaca dengan cukup cepat. Aplikasi antar muka mampu memberikan informasi berupa gambaran kondisi yang sebenarnya di lapangan melalui indikator yang ditampilkan.

\section{Daftar Pustaka}

[1] Novrian D. Rancang Bangun Alat Pencegah Kebakaran Dari Kebocoran Gas Menggunakan Sensor Mq135 Berbasis Mikrokontroler Atmega16. Palembang: Politeknik Negeri Sriwijaya, 2014.

[2] Christian, J. Prototipe Sistem Pendeteksi Kebocoran Gas LPG Menggunakan Sensor Gas MQ2, Board Arduino Duemilanove, Buzzer, dan Arduino GSM Shield pada PT. Alfa Retailindo (Carrefour Pasar Minggu). J TICom. 2013, 2(1).

[3] Ramady, GD, Hidayat R, Syafruddin R, Mahardika AG, Hakim RR, Sistem Monitoring Data pada Smart Agriculture System Menggunakan Wireless Multisensor Berbasis IoT, Prosiding Seminar Nasional Teknoka, 2019, p. E518.

[4] Ramady, GD. Bluetooth beacon battery monitoring system using LabView. Jurnal Online Sekolah Tinggi Teknologi Mandala, 2018, 13(2), pp.45-50.

[5] Amini, S. Rancang Bangun Sistem Pendeteksi Kebocoran Gas LPG Pada Rumah Tangga Berbasis Mikrokontoler. Politeknik Negeri Padang, 2018.

[6] Rakhman, A., \& Sutanto, A. (2018). Analisa Sistem Informasi Geografis Tempat Laundry Berbasis Android. Smart Comp: Jurnalnya Orang Pintar Komputer, 7(1).

[7] Prasetiawan A, Suparno D, Nurrahmah H. Sistem detektor kebocoran gas pada tabung LPG. Jurnal Jur Tek Elektro, Fak Tek UMS Surakarta, Surakarta.

[8] Rakhman, A., \& Anggraeni, D. M. (2018). Analisa Aplikasi Penggajian Pada Spbu Muri Tegal Menggunakan Visual Basic 6.0. Smart Comp: Jurnalnya Orang Pintar Komputer, 7(2), 286-291.

[9] Ramady, Givy Devira, Suherman A, Ramadhanti TS, Perancangan Aplikasi Digital Menu Kafe Coffe 86 Berbasis Desktop Menggunakan Visual Studio 2010, Prosiding Seminar Nasional Teknoka, 2019, p. I63-9. 